\title{
ANALISIS PENGARUH TRUST, APPLICATION QUALITY, PERCEIVED USEFULNESS TERHADAP INTENTION TO PURCHASE DAN ACTUAL SYSTEM USE (STUDI KASUS PADA APLIKASI KAI ACCESS)
}

\author{
Oleh : \\ Ahmad Rifaldi, Bintoro Tri Wicaksono, Dixsy Faturochman Putra \\ Universitas Bina Nusantara di Alam Sutera, Tangerang \\ Email: ahmadrifaldibl22@gmail.com
}

\begin{abstract}
Article Info
Article History:

Received 13 Sept - 2021

Accepted 25 Sept - 2021

Available Online 25 Sept 2021

Abstract

The purpose of this study is to determine the effect of trust, application quality, and perceived usefulness on the intention to purchase and actual system use of the KAI ACCESS application between the ages of 19 -39 years in Jabodetabek. From the 204 respondents obtained, data analysis was then carried out and the results showed that the trust variable did not have a significant effect on the intention to purchase, while the application quality and perceived usefulness variables had a significant influence on the intention to purchase variable, then the intention to purchase variable also had a significant effect. significant to the actual system use variable. From the analysis of the coefficient of determination, it is found that the variables of trust, application quality and perceived usefulness can explain the variable intention to purchase by $81.1 \%$, while the remaining $18.9 \%$ is explained by other variables and the variable intention to purchase can explain the actual system use variable of $52.5 \%$ and the remaining $47.5 \%$ is explained by other variables.
\end{abstract}

\author{
Keyword : \\ Trust, Application Quality, \\ Perceived Usefulness, \\ Intention To Purchase and \\ Actual
}

\section{PENDAhULUAN}

Saat ini era digital telah menjadi bagian dari kehidupan masyarakat. Perkembangan internet terus tumbuh dan berkembang, bahkan di indonesia mulai dari tahun 2000 dan 2011 ada peningkatan 50 juta pengguna atau tumbuh $1000 \%$ (Internet World Stats). Alasan mengapa internet saat ini menjadi sangat populer adalah karena internet menyediakan berbagai macam hal yang memenuhi berbagai macam kebutuhan individu yang ada di seluruh dunia, setiap individu dapat membaca berita, mengakses forum, obrolan online, dan juga untuk bisnis online. Secara perlahan teknologi menjadi bagian yang tidak terlepas dari individu karena fungsinya yang membuat hidup lebih mudah. Maka perlahan individu memiliki rasa ketergantungan dengan teknologi. Diawali dengan kehadiran ponsel yang hanya memungkinkan untuk telepon atau mengirim pesan. Setelah itu, lingkungan menuntut lebih dari sebuah fungsi ponsel yang hanya sekedar untuk mengirim pesan dan telepon. Oleh karena itu, seiring perkembangan era digital yang sangat cepat dan didukung dengan perkembangan internet yang tidak kalah cepat, maka ponsel telah berkembang pesat menjadi sebuah smartphone. Teknologi 
canggih telah memungkinkan smartphone memiliki fungsi baru yang lebih luas dibanding sekedar mengirim pesan dan telepon yang bisa membuat nyaman penggunanya, seperti belanja melalui smartphone bahkan melakukan pemesanan tiket perjalanan melalui smartphone.

Perkembangan smartphone berpengaruh di berbagai bidang salah satunya teknologi informasi dan komunikasi (Masamila et al. 2010). Perkembangan teknologi informasi dan komunikasi berkembang secara pesat sehingga membuat penggunaan teknologi informasi dan komunikasi menjadi sangat penting karena berpengaruh secara signifikan atas perubahan kebiasaan individu yang menuntut secara cepat dan akurat dalam menerima sebuah informasi dan komunikasi (Radcliffe, 2002). Sejumlah besar fitur yang ditawarkan oleh smartphone membantu membuat kehidupan sehari hari menjadi lebih mudah sehingga membuat individu ketergantungan dengan smartphone (Calzada \& Estruch 2011). Saat ini smartphone telah mendukung jasa layanan keuangan seperti bill payment, account transfers, person to person transfers, proximity payments at the point of sale, mobile marketing, ticketing, discounts atau kupon (Zhong, 2009).

Perkembangan sistem informasi dan komunikasi juga perlu didukung banyak faktor yang diharapkan dapat memberikan kesuksesan dari sistem informasi dan komunikasi itu sendiri yang tercermin melalui kepuasan dan kegunaan pemakaian sistem informasi dan komunikasi tersebut. Suatu sistem informasi dan komunikasi akan sukses apabila didukung oleh beberapa faktor pendukung lainnya, yaitu partisipasi pengguna (Chandrarin \& Indriantoro

1997). Perkembangan sistem informasi dan komunikasi tersebut dinilai dapat menjadi peluang bagi para pelaku bisnis untuk mengembangkan usahanya karena berdasarkan data statistik menunjukan bahwa Indonesia menempati posisi ke6 sebagai pengguna internet terbanyak, yaitu mencapai 123 juta pengguna.

Perkembangan sistem informasi dan komunikasi telah berhasil dimanfaatkan baik oleh PT. KAI dengan mengembangkan aplikasi resminya, yakni KAI Access. Hal ini juga didukung oleh pernyataan Edi Sukmoro selaku direktur utama PT. KAI dan dibuktikan dengan meningkatnya jumlah volume penumpang kereta api dari tahun ke tahun. Pada 2016, KAI berhasil membawa total sejumlah 352,3 juta penumpang. Di tahun 2017, jumlahnya meningkat sebesar 12\% menjadi 394,1 juta penumpang. Kemudian, pada tahun 2018 naik 8\% 425 juta dilanjutkan sampai dengan Semester I 2019, terjadi peningkatan sebesar $2 \%$ dibandingkan dengan periode yang sama di tahun sebelumnya.
Pada Semester I 2019 PT Kereta Api Indonesia (Persero) melayani 210,7 juta penumpang. Sedangkan di Semester I 2018, KAI melayani 207 juta penumpang.

PT. KAI sadar akan tuntutan dari konsumen yang menginginkan adanya informasi yang cepat dan akurat. Salah satu cara agar organisasi bisnis mampu bersaing dengan para kompetitornya adalah dengan menggunakan sistem informasi dan komunikasi, tidak sedikit organisasi bisnis yang mengeluarkan dana besar dalam investasi untuk sistem informasi dan komunikasi (Irwansyah, 2003).

Berdasarkan pernyataan tersebut, PT. KAI memberikan solusi terhadap permasalahan pemesanan tiket perjalanan kereta api dengan adanya pemesanan tiket secara elektronik. Penggunaan tiket elektronik telah berkembang pesat seiring dengan perkembangan teknologi informasi dan komunikasi, salah satunya di industri kereta api. Di Indonesia, antusiasme pengguna layanan transportasi kereta api dinilai masih tinggi terutama untuk yang berada di Pulau Jawa. Berdasarkan data dari Badan Pusat Statistik disebutkan bahwa pengguna kereta api di Pulau Jawa mencapai 35 juta orang pada bulan September 2019.

Oleh karena itu, terciptalah aplikasi KAI Access yang memungkinkan penggunanya dapat mengakses berbagai layanan dengan mudah. Online reservation, Online Cancelation, Online Reschedule, e-boarding pass, reservasi KA bandara, dan reservasi tiket KA Lokal adalah sedikit dari sekian banyak fitur dalam KAI Access. Jika ditarik ke masa lalu maka konsumen dihadapkan dengan kondisi antrian yang panjang serta harus datang langsung ke lokasi pembelian tiket dan memerlukan waktu yang tidak sedikit. Sekarang konsumen dapat memesan tiket tanpa harus mendatangi langsung lokasi pembelian tiket dan mengantri panjang, cara pemesanan relatif dipermudah sehingga harapannya konsumen akan lebih tertarik menggunakan aplikasi pemesanan tiket secara online. Selain itu, beberapa keuntungan lain

yang diberikan dengan adanya aplikasi ini adalah menghemat waktu, tenaga dan biaya dalam memperoleh tiket perjalanan kereta api yang akan dipesan. Sepanjang tahun 2018, volume pemesanan tiket perjalanan secara online mengalami peningkatan hingga 260 persen. Hal tersebut dapat menunjukan bahwa kehadiran tiket elektronik menjawab keresahan konsumen dan konsumen banyak diuntungkan dengan kehadiran tiket elektronik tersebut.

Namun, walaupun kehadiran aplikasi resmi dari PT. KAI yaitu KAI Access ini menjawab keresahan dan dinilai dapat menguntungkan konsumen, ternyata hal tersebut dimanfaatkan oleh perusahaan lain untuk membuat platformserupa, 
yaitu pemesanan tiket kereta api secara online. Saat ini, aplikasi untuk pemesanan tiket kereta api secara online tidak hanya KAI ACCESS saja, tetapi ada beberapa perusahaan yang memberikan layanan serupa. Hal tersebut tentunya membuat masyarakat pengguna kereta api akan memilih dan membandingkan aplikasi yang menurut mereka paling memuaskan. Tetapi, ditengah banyaknya kompetitor layanan pemesanan tiket kereta api secara online yang berlomba-lomba untuk memenangkan hati pelanggannya, KAI ACCESS sampai saat ini masih dapat bertahan dan tidak kalah jumlah penggunanya dengan aplikasi lain. Hal tersebut dibuktikan dengan naiknya penumpang kereta api dari tahun ke tahun sejak diluncurkannya aplikasi KAI ACCESS ini.

Selain itu, penerapan sistem e-ticketing ini berkaitan dengan penerimaan sistem informasi berbasis teknologi di masyarakat. Penerimaan sistem informasi berbasis teknologi didefinisikan bahwa individu berminat dan mau menggunakan sistem berbasis teknologi yang diimplementasikan (Kinanti, 2013). Dengan demikian, hal tersebut menimbulkan pertanyaan pada peneliti, mengapa masyarakat mau menggunakan aplikasi KAI ACCESS dalam melakukan pemesanan tiket kereta api. Oleh karena itu, untuk memperkuat masalah yang akan diangkat sehingga layak untuk diteliti, peneliti mencoba berdiskusi dengan salah satu pengguna aplikasi KAI Access dengan memberikan pertanyaan mengapa anda menggunakan KAI Access dan pengguna memberikan jawaban bahwa alasan ia menggunakan aplikasi tersebut adalah membawa rasa aman karena aplikasi tersebut langsung dikelola dari PT. KAI, informasi yang jelas mengenai pemesanan tiket perjalanan kereta api, dan menghemat waktu serta usaha. Berdasarkan jawaban tersebut, dapat ditarik kesimpulan bahwa ketiga alasan itu adalah dasar seseorang untuk menggunakan aplikasi KAI Access dan hal ini berkesinambungan dengan masalah yang sudah disampaikan sebelumnya bahwa kepercayaan, kualitas aplikasi, persepsi manfaat seseorang adalah faktor yang mendorong minat seseorang dalam menggunakan aplikasi dan menggunakannya kembali secara berulang.

Untuk meningkatkan pemahaman masalah, Peneliti menggunakan model TAM dan diimplementasikan pada aplikasi KAI Access. Tujuan dari penelitian ini adalah untuk menilai dan memverifikasi bahwa model TAM ini dapat digunakan untuk mengukur dan menjelaskan mengenai penerimaan aplikasi KAI Access. TAM adalah Technology Acceptance Model, salah satu model yang paling banyak digunakan untuk menjelaskan faktor-faktor berdampak pada penerimaan penggunaan sistem informasi dan mengukur penerimaan teknologi (Q.Ma \& L.Lin, 2004). TAM pertama kali dikenalkan oleh Davis mengenai konsep penerimaan teknologi (Davis, 1986). TAM adalah salah satu model yang paling banyak digunakan untuk menjelaskan faktor-faktor yang berdampak pada penerimaan pengguna terhadap sistem informasi. (Davis et al, 1986). TAM didasari oleh teori dari Fishbein dan Ajzen mengenai Reasoned Action model (Davis et al, 1986). TAM dikembangkan untuk menjelaskan pengaruh persepsi pengguna terhadap karakteristik sistem terhadap penerimaan pengguna sistem informasi (Davis, 1986). TAM menunjukkan bahwa ada dua kepercayaan yaitu Perceived Usefulness dan Perceived Ease of Use yang dirasakan paling relevan untuk perilaku sistem informasi yang diterima.

Davis mendefinisikan bahwa Perceived Usefulness dirasakan sebagai "Sejauh mana seseorang percaya bahwa menggunakan sistem tertentu akan meningkatkan kinerja pekerjaannya." (Davis ,1986) (Schultz \& Slevin ,1975), melakukan studi eksplorasi dan menemukan bahwa Perceived Usefulness dapat memberikan prediksi yang dapat diandalkan untuk menentukan decision model. Dan Perceived Ease of Use sebagai "Sejauh mana seorang individu percaya bahwa menggunakan sistem tertentu akan bebas dari upaya fisik dan mental." (Bandura, 1982) menunjukan pentingnya mempertimbangkan keduanya antara Perceived Ease of Use dan Perceived Usefulness dalam menentukan sikap seseorang. TAM mengusulkan bahwa sebelum mencapai tahap Actual System Use maka pengguna harus merasakan Intention to Purchase dan diawali dengan Perceived Usefulness yang mana didasarkan pada gagasan bahwa teknologi tertentu dapat bermanfaat bagi pengguna untuk mencapai tujuannya (Vijayasarathy, 2004). Model ini telah banyak diterapkan diberbagai bidang, seperti penggunaan layanan online (Liao et al, 2007), mobile phone (Ervasti \& Helaakoski, 2010), mobile ticketing (Mallat et al. 2009), social networking (Lorenzo et al. 2011), e-finance (Abroud et al. 2013).

Pada penelitian ini, peneliti tidak akan memakai keseluruhan model TAM. Hal tersebut dikarenakan hasil diskusi yang didapat dari pengguna KAI Access mengatakan ada faktor lain yang mempengaruhi ia menggunakan KAI Access (Intention to Purchase). Faktor tersebut sudah dijelaskan pada paragraf sebelumnya dan peneliti simpulkan alasan pertama menjadi variable Trust dan variable kedua menjadi Appplication Quality, serta alasan terakhir yaitu tetap dengan Percevied Usefulness. Dengan demikian, dari ketiga faktor tersebut kami asumsikan mempunyai hubungan dengan Intention to Purchase yang kemudian dilanjtkan pada Actual System Use berdasarkan pada 
model asli dari TAM.

\section{KAJIAN PUSTAKA DAN PEGEMBANGAN HIPOTESIS}

Trust

Trust merupakan salah satu hal yang sangat penting dalam sebuah bisnis. Suatu transaksi sebuah bisnis antara kedua belah pihak atau lebih akan terjadi apabila adanya rasa saling mempercayai satu sama lain. Trust ini tidak serta merta dapat diakui oleh pihak lain/mitra bisnis. Trust harus dipertimbangkan sebagai katalis dalam sebuah transaksi antara penjual dan pembeli agar kepuasaan konsumen dapat terwujud sesuai dengan yang diharapkan (Yousafazai et al.2003). Beberapa literatur telah mendefinisikan trust dengan berbagai pendekatan (Mukherjee dan Nath, 2003 ). Pada awalnya trust banyak dikaji dari kedisiplin psikologi, karena hal ini berkaitan dengan sikap sebuah individu. Pada perkembangannya trust menjadi kajian disiplin ilmu (Riegelsberger et al., 2003; Murphy dan Blessinger, 2003, Kim dan Tadisina, 2003), termasuk menjadi kajian dalam ecommerce.

Menurut Mayer et al. (1995) faktor yang membentuk kepercayaan seseorang terhadap sesuatu ada tiga yaitu kemampuan (ability), kebaikan hati (benevolence), dan integritas (integrity). Ketiga faktor tersebut dapat dijelaskan sebagai berikut:

1. Kemampuan (Ability). Kemampuan mengacu pada kompetensi dan karakteristik penjual/organisasi dalam mempengaruhi sesuatu yang spesifik. Kim et al. (2003a) menyatakan bahwa ability meliputi kompetensi, pengalaman, pengesahan institusional, dan kemampuam dalam ilmu pengetahuan.

2. Kebaikan hati (Benevolence). Kebaikan hati merupakan keinginan penjual dalam memberikan kepuasan yang saling menguntungkan antara dirinya dengan konsumen. Menurut Kim et al. (2003a), benevolence meliputi perhatian, empati, keyakinan, dan kemampuan menerima.

3. Integritas (Integrity). Integritas berkaitan dengan bagaimana sebuah perilaku atau kebiasaan penjual dalam menjalankan bisnisnya. Informasi yang diberikan kepada konsumen apakah sudah sesuai dengan fakta atau tidak. Kualitas produk yang dijual apakah dapat dipercaya atau tidak. Kim et al.(2003) mengemukakan bahwa integrity dapat dilihat dari sudut kewajaran (fairness), pemenuhan (fulfillment), kesetiaan (loyalty), kejujuran.

\section{Application Quality}

Maraknya penggunaan aplikasi untuk memenuhi kebutuhan membuat kualitas sebuah aplikasi mendapat perhatian dari para penggunanya. Aplikasi yang baik akan membuat para pengguna lebih tertarik untuk sering membuka aplikasi tersebut. Aladwani dalam Chang dan Cheng (2008) mendifinisikan bahwa kualitas sebuah aplikasi menjadii evaluasi pengguna dalam proses bertransaksi.

Kualitas sebuah aplikasi menurut Barnes dan Vidgen (2001) terdiri dari; (1) kualitas informasi aplikasi, dalam hal ini bagaimana sebuah aplikasi dapat memberikan informasi yang akurat, dan dapat dipercaya serta dapat dimengerti oleh penggunanya; (2) kualitas tampilan aplikasi, meliputi kemampuan aplikasi dalam pengaturan menu-menu, penataan warna serta kejelasan ukuran tulisan dalam aplikasi; (3) kualitas penggunaan, yaitu kemudahan dalam mengakses informasi dalam aplikasi. Amoroso dan Cheney (1992) juga berfokus pada kepuasan dari pengguna dan pada pemanfaatan aplikasi sebagai komponen application quality. Untuk meningkatkan application quality, developer aplikasi harus memberikan keputusan bagaimana menghubungkan evaluasi dengan proses desain yang memiliki tujuan untuk meningkatkan suatu prototype (Hornbæk, 2010). Perbedaan material konten, perbedaan ukuran desain aplikasi, dan lain-lain akan menjadi faktor penting dalam konteks evaluasi User Experience pada pengguna smartphone yang potensial (Ling et al., 2007).

Percevied Usefulness didefinisikan mengenai sejauh mana seseorang percaya bahwa menggunakan suatu teknologi akan meningkatkan pekerjaannya, Jogiyanto (2010:114). Menurut Adamson dan Shine (2003) mendefinisikan Percevied Usefulness sebagai konstruk keyakinan seseorang bahwa penggunaan sebuah teknologi tertentu akan mampu meningkatkan kinerja mereka. Dari definisi tersebut persepsi kegunaan dapat disimpulkan bahwa seseorang akan menggunakan sebuah teknologi apabila teknologi itu dapat memberikan pengaruh positif dan dapat meningkatkan kinerjanya.

Pada penelitian Davis (1986) yang berjudul "User acceptance of computer technology: a comparison of two theoretical models" mengukur indikator persepsi kegunaan, yaitu Pleasure a) menggunakan writeone dapat meningkatkan kinerja), b) menggunakan WriteOne meningkatkan produktifitas, c) Menggunakan WriteOne dapat meningkatkan efektivitas, d) Menggunakan WriteOne berguna dalam pekerjaan (Fang et al 2009) juga mengukur indikator Percevied Usefulness, yaitu 1) mampu meningkatkan kinerja individu, 2) mampu menambah tingkat produktivitas individu, dan 3) mampu meningkatkan efektivitas kinerja individu. 


\section{Intention to Purchase}

Kotler dan Keller (2008) menunjukkan bahwa Intention to Purchase adalah mekanisme kesediaan konsumen untuk membeli produk/jasa tertentu. Intention to Purchase memiliki berbagai variasi sesuai dengan stimulus, harapan hasil, nilai aspirasi, rekomendasi, dan asosiasi emosional (CobbWalgren, Ruble, Dontu., 1995). Intention to Purchase adalah kemungkinan bahwa konsumen akan membeli produk atau jasa tertentu, dan juga dihubungkan dengan pembelian berikutnya (C. Lee et al., 2011). Untuk menjaga komitmen konsumen yang membeli kembali suatu produk di masa yang akan datang, diluar dari usaha pemasaran, maka bisa dilakukan untuk memodifikasi perilaku pelanggan (Azeem dan Haq, 2012). Purchase Intention tidak hanya dipengaruhi oleh nilai suatu produk dan manfaatnya tetapi juga dari berbagai testimoni dari konsumen yang lainnya (Zhang et al., 2017).

\section{Actual System Use}

Actual System Use merupakan bentuk respon psikomotor eksternal yang dapat diukur dari seorang dengan penggunaan nyata (Davis, 1989). Actual System Use memiliki konsep pengukuran terhadap frekuensi dan 18 durasi waktu terhadap penggunaan teknologi (Wibowo, 2006). Sedangkan menurut Rigopoulos dan Askounis (2007) Actual System Use diukur berdasarkan penggunaan teknologi secara berulang-ulang dan lebih sering. Ditambahkan oleh Eriksson (2005) yang menyatakan bahwa Actual System Use internet banking dapat diukur dengan menggunakan indikator penggunaan nyata dalam transaksi bisnis, transaksi pribadi, dan dalam semua transaksi yang dilakukan di bank. Actual system use mengacu pada seberapa sering dan berapa banyak pengguna, selain itu dinyatakan bahwa niat perilaku seseorang sudah cukup untuk mempengaruhi actual system use. (Davis, 1989).

\section{Pengaruh antara Trust dan Intention to Purchase}

Niat membeli suatu barang atau jasa secara online dipengaruhi oleh kepercayaan dari konsumen yang akan melakukan pembelian secara online. Konsumen memiliki niat beli jika sudah merasa bahwa produk yang akan dibeli nantinya akan memberikan kenyamanan dan kepuasan. Kepercayaan terdapat pada layanan yang diberikan oleh perusahaan untuk konsumen, sehingga konsumen berniat melakukan untuk membeli barang baik jasa maupun produk yang ditawarkan oleh perusahaan. Hasil penelitian terdahulu mengenai kepercayaan terhadap niat beli juga didukung oleh $\mathrm{Li}$ et al. (2007) dengan hasil penelitian menemukan bahwa kepercayaan memiliki pengaruh yang signifikan dengan niat membeli. Kepercayaan konsumen yang lebih besar memotivasi pelanggan menghasilkan niat lebih untuk membeli di pusat perbelanjaan melalui internet. Li et al., (2007) juga menegaskan bahwa kepercayaan harus dibangun pertama jika e-vendor China ingin meningkatkan kompetensi situs Web- nya. Maka penelitian ini memiliki H1 yaitu:

H1: Trust memiliki pengaruh positif yang signifikan dengan Intention to Purchase Pengaruh antara Application Quality dan Intention to Purchase

Beberapa penelitian tentang kualitas sebuah aplikasi dapat mempengaruhi seseorang untuk melalukan transaksi di aplikasi tersebut. Chen (2013) menemukan kualitas sistem, kualitas informasi dan kualitas pelayanan berpengaruh signifikan terhadap niat bertransaksi pada mobile shopping. Sam dan Tahir (2009) meneliti kualitas website seperti kegunaan, desain, kualitas informasi, kepercayaan, persepsi resiko dan empati mempunyai pengaruh signifikan terhadap niat konsumen dalam pembelian tiket pesawat. Penelitian Ganguly (2010) menemukan adanya pengaruh signifikan antara kualitas aplikasi terhadap niat beli pada online shopping di Amerika Serikat. Lee dan Lin (2005) juga menemukan informasi yang berkualitas adalah faktor yang paling penting seorang pelanggan mempengaruhi perilaku untuk melakukan suatu pembelian. Maka penelitian ini memiliki H2 yaitu:

H2: Application Quality memiliki pengaruh positif yang signifikan dengan Intention to Purchase

Pengaruh antara Percevied Usefulness dan Intention to Purchase

Perceived Usefulness didefinisikan sebagai sejauh mana konsumen merasakan aplikasi akan meningkatkan kinerjanya (Davis, 1989). Kemudian dalam e-commerce khususnya e- ticketing persepsi tentang manfaat atau kegunaan merupakan keyakinan konsumen tentang sejauh mana dia akan menjadi lebih baik dari transaksi online dengan aplikasi tertentu (Kim, et.al, 2008). Maka penelitian ini memiliki H3 yaitu:

H3: Percevied Usefulness memiliki pengaruh positif yang signifikan dengan Intention to Purchase

Pengaruh antara Intention to Purchase dan Actual System Use 
Niat membeli kembali secara online adalah situasi ketika seorang pelanggan bersedia dan berniat untuk terlibat dalam transaksi kegiatan pembelian yang sering dilakukan karena adanya minat untuk membeli produk yang sudah pernah dikonsumsi serta sudah merasakan manfaat dan kegunaan jasa maupun produk tersebut (Pavlou, 2003). Keputusan pembelian pada masa lalu oleh konsumen akan berdampak pada masa mendatang, hal tersebut berupa pembelian kembali yang kemudian menginformasikan kinerja produk atau jasa yang dirasakannya kepada orang lain (Kuntjara, 2007).

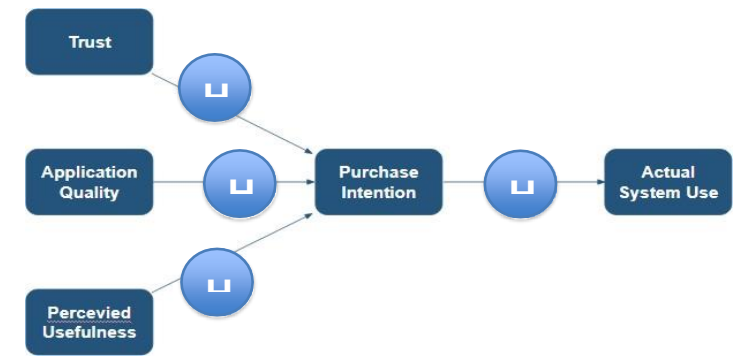

Maka penelitian kami memiliki $\mathrm{H} 4$ yaitu:

H4: Intention to Purchase memiliki pengaruh positif yang signifikan dengan Actual System Use Dari usulan hipotesis kami tersebut, maka berikut adalah gambar dari model penelitian kami:

\section{METODE PENELITIAN}

Metode penelitian yang digunakan pada penelitian ini adalah dengan pendekatan kuantitatif yang dimana dilakukan dengan mengumpulkan, mengolah, menyajikan dan menganalisis data secara kuantitatif agar dapat memberikan gambaran yang jelas tentang masalah yang di teliti. Populasi target penelitian ini merupakan Generasi Y (1980-2000) yang berdomisili di wilayah JABODETABEK dan pengguna atau pernah menggunakan aplikasi KAI ACCESS. Data yang digunakan untuk menguji penelitian ini dikumpulkan menjadi sampel dengan menggunakan metode Judgemental Sampling yaitu individu pengguna atau pernah menggunaakan aplikasi KAI ACCESS kemudian dilakukan filter kembali dengan menentukan usia sampel berdasarkan Generasi Y (19-39 tahun), setelah itu penentuan domisili sampel berdasarkan wilayah yaitu di JABODETABEK. Pengumpulan data dilakukan menggunakan metode survei dengan menyebarkan kuesioner online menggunakan Microsoft Forms.

Bagian pertama kuesioner berisi mengenai pertanyaan kepada responden apakah anda pengguna atau pernah menggunakan aplikasi KAI, jika sampel menjawab YA maka akan otomatis muncul pertanyaan selanjutnya yaitu apakah anda berusia
19-39 tahun, dan jika sampel menjawab YA, maka akan diarahkan ke kuesioner bagian kedua. Bagian kedua kuesioner lebih fokus untuk mengetahui data demografi responden. Di bagian kedua terdapat pertanyaan demografi mengenai domisili, jika sampel menjawab diantara wilayah JABODETABEK, maka itu adalah responden dari penelitian ini. Kemudian di bagian ketiga responden akan terfokus untuk mengisi item kuesioner yang berkaitan dengan variabel di kerangka penelitian ini. Data penelitian yang telah dikumpulkan berdasarkan hasil jawaban dari kuisioner yang disebar kemudian akan diolah dengan menggunakan bantuan software Smart PLS.

Item kuesioner yang dipilih menggambarkan tentang konsep penelitian secara umum untuk memastikan validitas dari masing-masing variabel. Maka dari itu, item kuesioner yang dipilih dari masing - masing variabel diadaptasi dari penelitian sebelumnya. Enam item kuesioner yang sudah disesuaikan untuk variabel Trust diadaptasi dari Suh \& Han (2002) yang juga melakukan adaptasi kuesioner dari Mayer et al. (1995). Selanjutnya untuk mengukur variabel Application Quality peneliti menggunakan delapan item kuesioner yang sudah diadaptasi dari (Chang et al., 2014; Kassim dan Abdullah, 2010; Barnes dan Vidgen, 2001). Untuk mengukur variabel Perceived Usefulness peneliti memilih empat item kuesioner yang sudah disesuaikan dan diadaptasi dari (Alharbi dan Drew, 2014; Davis, 1993). Selanjutnya variabel Intention to Purchase juga diukur menggunakan 4 item kuesioner yang diadaptasi dari Huang et al. (2010) dan juga hasil adaptasi dari Haley and Case (1979), Shimp et al. (1991). Ada empat item kuesioner yang telah diadaptasi dari Fitriani et al. (2016) dan digunakan untuk mengukur variabel Actual System Use. Untuk semua item kuesioner peneliti menggunakan skala likert (1-5) mulai dari "sangat tidak setuju" sampai dengan "sangat setuju". Item kuesioner yang telah dipilih sudah diadaptasi sehingga relevan dengan area penelitian mengenai $e$ ticket.

\section{HASIL DAN PEMBAHASAN}

Data demografi responden yang berhasil didapat telah dikumpulkan ke dalam tabel (x) yang didominasi oleh wanita $(61 \%)$. Usia yang mendominasi adalah antara 19 - 24 tahun (56\%) Jakarta menjadi kota yang mendominasi yaitu sebesar (38\%). Pendidikan terakhir didominasi oleh SMA (45\%). Dan karakteristik pekerjaan didominasi oleh Pegawai Swasta (47\%).

Berdasarkan hasil perhitungan, $\mathrm{H} 2, \mathrm{H} 3, \mathrm{H} 4$ menunjukan hasil positif untuk hipotesisnya karena memiliki $p$-value kurang dari 0.05 dan value of beta yang positif. Sedangkan H1 (Trust) mengalami 
penolakan dari model struktural. $\mathrm{R}$ square menunjukan hasil 0.811, yang berarti bahwa variable seperti Trust, Application Quality, Perceived Usefulness dapat dijelaskan sebesar $81,1 \%$ pada penelitian ini. Selanjutnya Intention to Purchase secara signifikan berkontribusi sebesar 52,5\% ke actual system use.

Berdasarkan dari variable yang mempengaruhi yaitu dapat dikatakan bahwa variable Perceived Usefulness mempunyai efek yang paling signifikan dibandingkan dengan variable lainnya dengan beta values sebesar 0.620. Kemudian disusul variable Application Quality dengan nilai beta 0.269. Diluar dugaan ditemukan bahwa variable Trust tidak memiliki dampak yang signifikan dalam variable Intention to Purchase oleh karena itu berarti hanya variable Application Quality dan Perceived Usefulness yang dominan mempengaruhi variable Intention to Purchase.

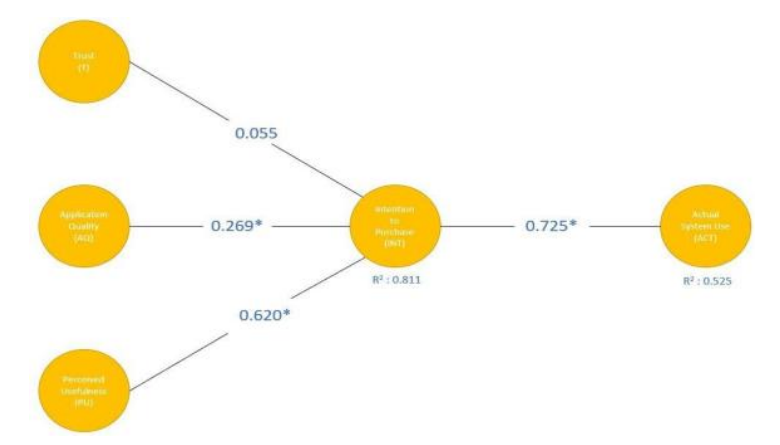

Table (X) menjelaskan mengenai model struktur yang sudah dibuat sebelumnya. Suatu hipotesis bisa diterima jika p-value lebih kecil dari 0.05 atau tvalue lebih besar dari 1.96 dan nilai koefisiennya menunjukkan angka positif. Setelah dijalani suatu tes terhadap model struktur diatas, maka didapatkan hasil bahwa Hipotesis 1 ditolak karena memiliki pvalue lebih besar dari 0.05 dan T-value lebih kecil dari 1.96. Sedangkan hipotesis 2, 3 dan 4 diterima karena memiliki p-value lebih kecil dari 0.05, Tvalue lebih besar dari 1.96 dan memiliki nilai koefisien yang positif. Dibawah ini adalah tabel dari hasil perhitungan yang sudah dilakukan

Table 4. Hasil Uji Hipotesis

\begin{tabular}{llcccl}
\hline Hypothesis & Connection & a & $\begin{array}{c}\text { T - } \\
\text { Statistic }\end{array}$ & $\begin{array}{c}\text { V } \\
\text { Values }\end{array}$ & Conclusion \\
\hline H1 & TR -> INT & 0.055 & 0,456 & 0.649 & Not Supported \\
\hline H2 & AQ -> INT & 0.269 & 2,909 & 0.004 & Supported \\
\hline H3 & PV -> INT & 0.620 & 5,649 & 0.000 & Supported \\
\hline H4 & INT -> ACT & 0.725 & 10,521 & 0.000 & Supported \\
\hline
\end{tabular}

\section{Pembahasan}

Setelah melakukan uji hipotesis pada model struktur penelitian didapatkan hasil bahwa variable Trust tidak memiliki pengaruh yang signifikan terhadap variable Intention to Purchase. Hal tersebut didukung oleh hasil perhitungan pada tabel (3), bahwa nilai p-value (0.649) lebih besar dari 0.05 dan $\mathrm{t}$-value (0.456) lebih kecil dari 1.96 maka H1 ditolak. Trust merupakan salah satu hal yang sangat penting dalam sebuah bisnis. Suatu transaksi sebuah bisnis antara kedua belah pihak atau lebih akan terjadi apabila adanya rasa saling mempercayai satu sama lain. Trust harus dipertimbangkan sebagai katalis dalam sebuah transaksi antara penjual dan pembeli agar kepuasaan konsumen dapat terwujud sesuai dengan yang diharapkan (Yousafazai et al.2003). Menurut Kim et al. (2003) faktor yang membentuk kepercayaan seseorang terhadap sesuatu ada tiga yaitu kompetensi, kejujuran, dan kepentingan pengguna. Ketiga indikator tersebut menjadi dasar penelitian ini dalam menentukan kuesioner yang akan di sebar. Konsumen memiliki niat beli jika sudah merasa bahwa produk yang akan dibeli nantinya akan memberikan kenyamanan dan kepuasan. Kepercayaan terdapat pada layanan yang diberikan oleh perusahaan untuk konsumen, sehingga konsumen berniat melakukan untuk membeli barang baik jasa maupun produk yang ditawarkan oleh perusahaan. Melihat hasil penghitungan data melalui Smart PLS dapat dijelaskan bahwa, walaupun hasil hitung variable Trust terhadap Intention to Purchase tidak sampai melebihi batas minimum, bukan berarti Trust tidak memiliki hubungan dengan Intention to Purchase. Hasil hitung masih tetap mendapatkan angka yang positif, sehingga hal ini bisa dikatakan bahwa Trust tetap memiliki pengaruh terhadap Intention to Purchase tetapi nilainya tidak besar karena ada variable lain yang memiliki nilai lebih besar dalam mempengaruhi Intention to Purchase. Maka menurut kesimpulan kami, variable Trust tidak menjadi pilihan utama pengguna KAI ACCESS dalam niat menggunakan aplikasi KAI ACCESS. Hal tersebut bisa dikarenakan saat ini metode pembelian tiket secara online sudah menjadi kebiasaan baru dalam masyarakat, sehingga ketakutan akan hal-hal yang tidak diinginkan sudah di kesampingkan. Ditambah lagi KAI ACCESS dikelola langsung oleh PT. KAI, maka hal tersebut menjadikan faktor kepercayaan juga semakin di kesampingkan. Masyarakat saat ini lebih melihat performa dari aplikasi tersebut dan sejauh mana fungsi yang diberikan oleh aplikasi tersebut.

Setelah dilakukan uji hipotesis pada model struktur penelitian didapatkan hasil bahwa variable Application Quality memberikan pengaruh yang signifikan serta positif terhadap variable Intention to Purchase. Hal tersebut didukung oleh hasil perhitungan pada tabel (x), bahwa nilai p-value (0.004) lebih kecil dari 0.05 dan t-value (2.909) lebih besar dari 1.96 maka H2 diterima. Chen (2013) 
menemukan bahwa kualitas sistem, informasi dan pelayanan memiliki pengaruh yang signifikan terhadap minat individu melakukan transaksi pada mobile shopping. Kualitas sistem dapat dinilai pada seberapa baik kemampuan perangkat keras, perangkat lunak dan kebijakan prosedur dari sistem informasi yang dapat menyediakan apa yang dibutuhkan oleh individu atau pemakai aplikasi. Sam dan Tahir (2009) meneliti kualitas website seperti kegunaan, desain, kualitas informasi dan kepercayaan memiliki pengaruh signifikan terhadap niat konsumen dalam melakukan pembelian tiket alat transportasi. Melihat hasil penghitungan data melalui Smart PLS telah dijelaskan bahwa Application Quality memiliki pengaruh yang positif dan signifikan dengan Intention to Purchase. Maka dapat disimpulkan bahwa layanan yang diberikan PT. KAI melalui KAI Access sudah meningkatkan niat beli masyarakat melalui aplikasi. Hasil ini dapat dijadikan indikator bahwa kehadiran aplikasi KAI Access sudah cukup meningkatkan niat masyarakat untuk membeli tiket melalui aplikasi. Hal ini juga sejalan dengan teori yang dipaparkan mengenai Application Quality, bahwa KAI ACCESS dirasa sudah memenuhi dan menyediakan apa yang dibutuhkan oleh pengguna KAI ACCESS. Serta pengaruh Application Quality terhadap Intention to Purchase juga tervalidasi

\section{Pengaruh Percevied Usefullness terhadap Intention to Purchase}

Setelah melakukan uji hipotesis pada model struktur penelitian didapatkan hasil bahwa variable Perceived Usefulness memiliki pengaruh yang positif dan signifikan terhadap variable Intention to Purchase. Hal tersebut didukung oleh hasil perhitungan pada tabel $(\mathrm{x})$, bahwa nilai p-value (0.000) lebih kecil dari 0.05 dan t-value (5.649) lebih besar dari 1.96 maka H3 diterima. Menurut (Davis, 1989) Perceived Usefulness dapat diartikan sebagai sejauh mana konsumen merasakan manfaat dari aplikasi yang akan meningkatkan kinerjanya. Dari hasil analisis yang didapat menunjukkan bahwa Perceived Usefulness dari aplikasi KAI Access dapat memberikan manfaat bagi penggunanya. Sehingga dari hasil penelitian ini dapat disimpulkan bahwa konsumen sudah merasakan manfaat yang positif ketika menggunakan aplikasi KAI Access.

Perceived Usefulness bermanfaat sebagai sejauhmana seseorang percaya bahwa penggunaan suatu teknologi akan meningkatkan kinerja pekerjaannya. Manfaat ketika menggunakan teknologi informasi dapat diketahui dari kepercayaan pengguna teknologi informasi tersebut dalam memutuskan penerimaan teknologi informasi, dan satu kepercayaan bahwa penggunaan teknologi informasi tersebut memberikan kontribusi yang positif bagi penggunanya (Jogiyanto, 2007). Suatu sistem dengan manfaat yang tinggi akan membuat pengguna percaya pada hubungan di antara perceived usefulness dengan intention to purchase. Seseorang yang telah menerima, menggunakan, dan merasakan manfaat dari kehadiran suatu teknologi informasi atau aplikasi KAI Access maka secara tidak langsung akan meningkatkan minat beli melalui aplikasi yang dianggap mempunyai manfaat atau telah membantu meningkatkan kinerja pekerjaannya. Hal tersebut memberi sugesti bahwa teknologi dalam lingkungan kerja akan meningkatkan produktivitas pengguna, kinerja pekerjaan, dan manfaat serta efektifitas kerja (Wibowo, 2008). Dari hasil analisis yang didapat menunjukkan bahwa Perceived Usefulness dari aplikasi KAI Access dapat memberikan manfaat bagi penggunanya. Sehingga dari hasil penelitian ini dapat disimpulkan bahwa konsumen sudah merasakan manfaat yang positif ketika menggunakan aplikasi KAI Access.

Setelah melakukan uji hipotesis pada model struktur penelitian didapatkan hasil bahwa variable Intention to Purchase memiliki pengaruh yang positif dan signifikan terhadap variable Actual System Use. Hal tersebut didukung oleh hasil perhitungan pada tabel (x), bahwa nilai p-value (0.000) lebih kecil dari 0.05 dan t-value (10.521) lebih besar dari 1.96 maka H4 diterima. Menurut (Kotler and Keller, 2008) menunjukkan bahwa Purchase Intention adalah mekanisme kesediaan konsumen untuk membeli produk/jasa tertentu. Purchase Intention memiliki beberapa variasi indikator harapan hasil dan rekomendasi (CobbWalgren et al., 1995). Maka dapat disimpulkan dari hasil penelitian bahwa berdasarkan teori sebelumnya harapan hasil dan rekomendasi menjadi indikator yang menentukan konsumen memiliki Intention to Purchase pada aplikasi KAI Access. Berdasarkan hasil yang diperoleh peneliti dalam penelitian ini menjelaskan bahwa munculnya perilaku individu untuk menggunakan layanan pemesanan tiket kereta api melalu aplikasi KAI Access dipengaruhi dari munculnya niat awal terhadap system pemesanan tiket kereta api melalu aplikasi KAI Access. Niat penggunaan merupakan representasi sukarela dan kesiapan kognitif pengguna untuk benarbenar menggunakan layanan pemesanan tiket kereta api melalu aplikasi KAI Access. Niat awal yang positif akan mendorong perilaku yang semakin besar untuk menggunakan layanan pemesanan tiket kereta api melalu aplikasi KAI Access namun apabila niat awal yang terbentuk adalah negatif, maka akan dapat mengurangi perilaku seseorang untuk menggunakan sistem layanan pemesanan tiket kereta api melalu aplikasi KAI Access. Dengan kata lain, seseorang akan menggunakan layanan pemesanan tiket kereta 
api melalu aplikasi KAI Access jika telah memiliki niat awal untuk menggunakan layanan pemesanan tiket kereta api melalu aplikasi KAI Access. Hasil penelitian ini mendukung hasil penelitian yang dilakukan oleh Leng et al. (2011) dan Bouwman (2011), di mana niat penggunaan berpengaruh secara signifikan positif terhadap penggunaan aktual.

\section{KESIMPULAN}

Berdasarkan penelitian yang telah dilakukan, setelah melalui tahap pengumpulan data, pengolahan data, analisis data dan yang terakhir interpretasi hasil, aplikasi KAI ACCESS masih kurang mendapat kepercayaan karena masyarakat menilai KAI ACCESS masih belum memberikan pelayanan yang kurang maksimal sehingga kenyamanan dan kepuasan masyarakat masih belum didapat. Tetapi dari sisi kualitas aplikasi dan persepsi manfaat, masyarakat menilai aplikasi KAI ACCESS telah memenuhi kriteria untuk keduanya, salah satu contohnya adalah masyarakat merasa aplikasi KAI ACCESS memberikan informasi yang diinginkan masyarakat. Adanya aplikasi KAI ACCESS untuk memesan tiket kereta api, masyarakat juga merasa terjadi peningkatan dalam produktivitas kerja mereka. Dengan demikian, penggunaan system secara actual (KAI ACCESS) telah dilakukan masyarakat ketika mereka membutuhkan sebuah transportasi yaitu kereta api untuk perjalanannya. Hal ini dikarenakan adanya kualitas aplikasi dan persepsi kemudahan yang memenuhi kriteria sehingga membuat masyarakat mempunya niat untuk menggunakan KAI Access.

\section{REFERENSI}

Abroud, A., Choong, Y. V., Muthaiyah, S., \& Fie, D. Y. G. (2013). Adopting e-finance: decomposing the technology acceptance model for investors. Service Business, 9(1), 161-182.

Adamson, I., \& Shine, J. (2003). Extending the New Technology Acceptance Model to Measure the End User Information Systems Satisfaction in a Mandatory Environment. A Bank's Treasury. Technolgy Analysis \& Strategic Management. 15(4), 441-455.

Alharbi, S., \& Drew, S. (2014). Using the Technology Acceptance Model in Understanding Academics' Behavioural Intention to Use Learning Management Systems. International Journal of Advanced Computer Science and Applications, 5(1).

Aladwani, A. M., \& Palvia, P. C. (2002). Developing and validating an instrument for measuring user-perceived web quality. Information \& Management, 39(6), 467-476.

Averweg, U. (2008). Information Technology
Acceptance in South Africa: An Investigation of Perceived Usefulness, Perceived Ease of Use, and Actual System Use Constructs. The African Journal of Information Systems, 1(1), 44-66.

Bandura, A. (1982). Self-efficacy mechanism in human agency. American Psychologist, 37(2), 122-147.

Barnes, S.J., \& Vidgen, R.T. (2000). WebQual: An Exploration of Web-Site Quality. ECIS.

Barnes, S. J., \& Vidgen, R. T. (2001). Assessing the Quality of Wap News Sites: The Webqual/M Method. Vision: The Journal of Business Perspective, 5(1), 81-91.

Calzada, J. and A. Estruch. (2011). "Telefonía móvil en España: regulación y resultados." Cuadernos Económicos de ICE, 81, 39-70.

Carissa, A., Natalia, J., \& Gunadi, W. (2020). Understanding The Role Of Sensory, Emotional, Social And Memorable Experiences In Behavioural Intention Of Indonesia's Music Concert Industry. International Journal of Scientific \& Technology Research, 9(01), 370-381.

Chandrarin, Grahita dan Indriantoro, N. (1997). Hubungan antara Partisipasi dengan Kepuasan Pemakai dalam Pengembangan Sistem Berbasis Komputer: Suatu Tinjauan Dua Faktor Kontijensi, Jurnal Ekonomi dan Bisnis Indonesia, 12(2), 15-35.

Chang, K.-C. (2014). The Impact of Website Quality and Perceived Trust on Customer Purchase Intention in the Hotel Sector: Website Brand and Perceived Value as Moderators. International Journal of Innovation, Management and Technology.

Chen, L. Y. (2013). Antecedents of customer satisfaction and purchase intention with mobile shopping system use. International Journal of Services and Operations Management, 15(3), 259.

Consumer Acceptance of Electronic Commerce: Integrating Trust and Risk with the Technology Acceptance Model. (2003). International Journal of Electronic Commerce, 7(3), 101-134.

Davis, Fred. (1985). A Technology Acceptance Model for Empirically Testing New EndUser Information Systems.

Davis, F. D., Bagozzi, R. P., \& Warshaw, P. R. (1989). User Acceptance of Computer Technology: A Comparison of Two Theoretical Models. Management Science, 35(8), 982-1003.

Davis, F. D. (1993). User acceptance of information technology: system characteristics, user perceptions and behavioral impacts. 
International Journal of Man-Machine Studies, 38(3), 475-487.

Ervasti, M., \& Helaakoski, H. (2010). Case study of application-based mobile service acceptance and development in Finland. International Journal of Information Technology and Management, 9(3), 243.

Fitriyani, A., Sfenrianto, S., Wang, G., \& Susanto, A. (2016). Examining the Security Issues of Automated Teller Machine Based on Revised Technology Acceptance Model. Telkomnika (Telecommunication Computing Electronics and Control), 14(4), 1521-1526.

Ganguly, B., Dash, S. B., Cyr, D., \& Head, M. (2010). The effects of website design on purchase intention in online shopping: the mediating role of trust and the moderating role of culture. International Journal of Electronic Business, 8(4/5), 302.

Huang, C.-Y., Chou, C.-J., \& Lin, P.-C. (2010). Involvement theory in constructing bloggers intention to purchase travel products. Tourism Management, 31(4), 513-526.

Irwansyah, (2003). Evaluasi Pemakai Atas Kecocokan Tugas Teknologi yang Mempengaruhi Kinerja Individu, Thesis, Universitas Gadjah Mada.

Kassim, N., \& Abdullah, N. A. (2010). The effect of perceived service quality dimensions on customer satisfaction, trust, and loyalty in ecommerce settings. Asia Pacific Journal of Marketing and Logistics, 22(3), 351-371.

Liao, C., Chen, J.-L., \& Yen, D. C. (2007). Theory of planning behavior (TPB) and customer satisfaction in the continued use of e-service: An integrated model. Computers in Human Behavior, 23(6), 2804-2822.

Lee, G. and H. Lin. (2005). "Customer Perceptions of E-Service Quality in Online Shopping”, International Journal of Retail and Distribution Management, 33(2), 161-176.

Ma, Q., \& Liu, L. (2004). The Technology Acceptance Model. Journal of Organizational and End User Computing, 16(1), 59-72.

Mallat, N., Rossi, M., Tuunainen, V. K., \& Öörni, A. (2009). The impact of use context on mobile services acceptance: The case of mobile ticketing. Information \& Management, 46(3), 190-195.

Masamila, B., Mtenzi, F., Said, J., \& Tinabo, R. (2010). A Secured Mobile Payment Model for Developing Markets. Networked Digital Technologies Communications in Computer and Information Science, 175-182.
Mukherjee, A. and Nath, P. (2003). A Model of Trust in Online Relationship Banking. The International Journal of Bank Marketing Bradford, 21(1), 5-15.

Park, B.-W., \& Lee, K. C. (2011). Exploring the value of purchasing online game items. Computers in Human Behavior, 27(6), 2178-2185.

Radcliffe, D. (2002). "Technological and pedagogical convergence betweenworkbased and campus-based learning." Educational Technology \&Society, 5(2), 5459.

Riegelsberger, J., Sasse, M., \& Mccarthy, J. D. (2003). The researchers dilemma: evaluating trust in computer-mediated communication. International Journal of Human-Computer Studies, 58(6), 759-781.

Rigopoulos, George., and Dimitrios Askounis. (2007). A TAM Framework to EvaluateUser's Perception Toward Online Electronic Payments. Journal of Internet Banking and Commerce, 12(3), 1-5.

Rong, L. (2007). The Effects Of Internet Shoppers Trust On Their Purchasing Intention In China. JISTEM Journal of Information Systems and Technology Management, 4(3), 269-286.

Romero, C. L., María Del Carmen Alarcón De Amo, \& Borja, M. Á. G. (2011). Adopción de redes sociales virtuales: ampliación del modelo de aceptación tecnológica integrando confianza y riesgo percibido. Cuadernos De Economía y Dirección De La Empresa, 14(3), 194-205.

Schultz, R. L., \& Slevin, D. P. (1975). Implementation and organizational validity: an empirical investigation. West Lafayette, IN: Krannert Graduate School of Industrial Administration, Purdue University.

Suh, B., \& Han, I. (2002). Effect of trust on customer acceptance of Internet banking. Electronic Commerce Research and Applications, 1(34), 247-263.

Vijayasarathy, L. R. (2004). Predicting consumer intentions to use on-line shopping: the case for an augmented technology acceptance model. Information \& Management, 41(6), 747-762.

Yousafzai, S. Y., Pallister, J. G., \& Foxall, G. R. (2003). A proposed model of e-trust for electronic banking. Technovation, 23(11), 847-860. 
Zhong, Junying. (2009). A Comparison of Mobile Payment Procedures in Finnish and Chinese

Markets. 